\title{
Concepções de professoras dos anos iniciais do ensino fundamental sobre prevenção do uso indevido de drogas
}

\author{
JULIA CHAMUSCA CHAGAS \\ Universidade de Brasília, Brasília, DF, Brasil \\ RICARDO HENRIQUE BRITO MARQUES \\ Universidade de Brasília, Brasília, DF, Brasil \\ REGINA LÚCIA SUCUPIRA PEDROZA \\ Universidade de Brasília, Brasília, DF, Brasil \\ LÚCIA HELENA CAVASIN ZABOTTO PULINO \\ Universidade de Brasília, Brasília, DF, Brasil \\ SANDRA FRANCISCA LIMA DA SILVA \\ Universidade de Brasília, Brasília, DF, Brasil \\ ISABELLE BORGES SIQUEIRA \\ Universidade de Brasília, Brasília, DF, Brasil \\ TAÍSA RESENDE SOUSA \\ Universidade de Brasília, Brasília, DF, Brasil \\ MARIA FÁTIMA OLIVIER SUDBRACK \\ Universidade de Brasília, Brasília, DF, Brasil
}

RESUMO

Partiu-se da concepção de escola como lugar de formação de aprendizes na relação com educadores, privilegiado para trabalhar questões relevantes à vivência social, como o uso de drogas, desde o início da escolarização. Objetivou-se levantar concepções de professoras dos anos iniciais do ensino fundamental que participaram da quinta edição do curso de prevenção ao uso de drogas para educadores de escolas públicas sobre os conteúdos abordados e sua prática cotidiana. Buscou-se refletir sobre a importância de criar formas pedagógicas pautadas no acolhimento às vivências das crianças. Realizou-se entrevistas com vinte e uma professoras ex-cursistas do Distrito Federal. A análise das categorias construídas permitiu refletir sobre a prática educativa cotidiana e a necessidade da escuta dos discursos das crianças sobre as drogas. As professoras puderam perceber que há abertura para abordar essas questões e demandaram formação teórico-prática como instrumento que auxilie o trabalho pedagógico.

PALAVRAS-CHAVES

escola; formação de professores; drogas; infância. 


\title{
CONCEPTIONS OF ELEMENTARY SCHOOL TEACHERS ABOUT DRUG ABUSE PREVENTION
}

\begin{abstract}
This study is based on the conception of school as a place of education where apprentices establish a relation to educators and as privileged setting to work issues relevant to social life, such as drug use, since the beginning of schooling. The goal was to raise conceptions of elementary school teachers who participated in the fifth edition of the course for drug abuse prevention for public school educators, on the content covered and on their daily teaching practice. We sought to bethink the importance of creating educational ways guided by the embracement of children's experiences. Interviews were conducted with twenty-one teachers from the Federal District who previously participated in the course. The analysis allowed thinking over everyday educational practices and the necessity of listening to children's discourses about drugs. The teachers were able to realize that there is openness for addressing these issues and demanded theoretical and practical education as a tool to assist on their pedagogical work.
\end{abstract}

\section{KEYWORDS}

school; teacher education; drugs; childhood.

\section{LAS CONCEPCIONES DE PROFESORAS DE LA ENSEÑANZA PRIMARIA SOBRE LA PREVENCIÓN DEL USO INDEBIDO DE DROGAS}

\section{RESUMEN}

La investigación partió de la concepción de escuela como espacio de formación de aprendices en relación con los educadores, privilegiado a trabajar cuestiones relevantes a la vida social, tales como el consumo de drogas, desde el inicio de la escolarización. Hubo como objetivo la búsqueda de las concepciones de profesoras de los años iníciales de la enseñanza primaria de escuelas públicas, participantes de la quinta edición del curso de prevención de abuso de drogas para educadores de la escuela pública, sobre los contenidos abordados en el curso y su práctica pedagógica diaria. Fueron entrevistadas veinte y una profesoras del Distrito Federal que hicieron el curso. El análisis de las categorías construidas permitió reflexionar sobre la práctica educativa cotidiana y la necesidad de escuchar los discursos de los niños sobre las drogas. Las profesoras fueron capaces de percibir que hay la posibilidad de abordar estas cuestiones y pidieron formación teórica y práctica como algo para ayudarlas en su trabajo.

PALABRAS CLAVE

escuela; formación de profesores, drogas; infância. 


\section{INTRODUÇÃO}

A escola é um espaço de constituição de sujeitos que cumpre a função primordial de construção do conhecimento formal de acordo com políticas educacionais estabelecidas pelos interesses da sociedade (Pedroza, 2003). Dessa forma, esse espaço vai além da transmissão de saberes, tornando-se o local de desenvolvimento de recursos de personalidade e de ações de promoção de saúde (Sudbrack e Dalbosco, 2005).

De acordo com essas concepções, é fundamental realizar uma formação em serviço de professores que contemple o seu desenvolvimento enquanto pessoa (Pedroza, 2003) para lidar com as questões cotidianas. Ao retomar a origem da escola e a sua inserção histórica na sociedade, perceberemos a relação que pode ser estabelecida entre a instituição escolar e o conceito de infância. Entendemos que as crianças são sujeitos ativos em seu processo de desenvolvimento e de constituição subjetiva, englobando suas especificidades do aqui e agora, considerando suas possibilidades de um tornar-se futuro, enfatizando que elas são, desde sempre, cidadãs de direitos e deveres (Sousa, Pedroza e Sousa, 2014).

$\mathrm{Na}$ origem da escola, não havia uma diferenciação e separação de idade por séries. Apenas no século XVII, surge um movimento de mudança sobre a forma de educação dos indivíduos. Nesse contexto, a escola tornou-se um espaço utilizado para educar as crianças, definindo, sobretudo, o prolongamento da infância de acordo com a duração do ciclo escolar. No início dos tempos modernos, a escola se apresentava como um espaço de isolamento das crianças, durante um período de formação intelectual e moral. Desse modo, conjugava-se como uma forma de adestrá-las com uma disciplina autoritária e, assim, separá-las dos adultos (Ariès, 1981).

Nesse sentido, reconhecemos a necessidade de transformações na estrutura e funcionamento da escola como possibilidade de acolhimento das vivências de cada estudante com as drogas e para o desenvolvimento de ações para promover condições de lidar criticamente com a realidade de substâncias psicoativas no contexto escolar (Camarotti, Kornblit e Di Leo, 2013; Masschelein e Simons, 2013).

Levando em consideração essas ideias, partimos da proposta do curso de prevenção ao uso de drogas para educadores de escolas públicas para a realização deste estudo. O curso é realizado pelo Programa de Estudos e Atenção às Dependências Químicas do Departamento de Psicologia Clínica do Instituto de Psicologia da Universidade de Brasília (PRODEQUI/PCL/IP/UnB) em parceria com a Secretaria Nacional de Políticas sobre Drogas (SENAD) e o Ministério da Educação (MEC).

O curso foi uma iniciativa da SENAD em parceria com o MEC e tem como objetivo a formação de professores para atuarem segundo o paradigma da prevenção do uso de drogas nas escolas onde trabalham. O curso é disposto em quatro módulos didáticos e um quinto prático, objetivando aperfeiçoar a escrita do projeto final e realizar a socialização na comunidade escolar.

Dessa forma, esta pesquisa objetivou levantar as concepções de professoras do ensino fundamental, dos anos iniciais, que participaram da quinta edição do curso de prevenção ao uso de drogas para educadores de escolas públicas sobre 
os conteúdos abordados e a relação deles com sua prática cotidiana. Além disso, buscamos refletir sobre a importância da experiência das professoras na pesquisa diária sobre a sua prática para a construção de possibilidades de uma educação na relação próxima e cotidiana com as crianças, criando formas pedagógicas dentro da temática da prevenção ao uso de drogas pautadas no acolhimento às vivências das crianças com as drogas e na escuta do que elas mesmas dizem sobre si e sua vida.

Tal pesquisa partiu de uma fundamentação teórico-metodológica baseada na perspectiva histórico-cultural (Vygotsky, 2000) que considera a educação e o desenvolvimento da pessoa um processo de construção de uma consciência crítica que permite a tomada de decisões autônomas em relação ao uso indevido de drogas. Além disso, ela se fundamenta na concepção de redução de danos (Sudbrack, 2014), assumindo que as drogas fazem parte da sociedade (álcool, café, medicamentos etc.) e, portanto, não devem ser vistas como um mal a ser combatido (Moreira, 2006). Nesse sentido, utilizamos o termo "prevenção ao uso indevido de drogas" para salientar que nem todo uso de drogas é considerado danoso. A questão é criar condições para que cada sujeito possa estabelecer uma relação de autonomia diante doo uso de drogas visando reduzir os danos a si mesmo e aos outros.

Com isso, ressaltamos a importância da formação de professores do ensino fundamental, desde os anos iniciais, para construir e manter uma escola democrática, autônoma e de qualidade para a formação de cidadãos críticos, participativos e aptos a problematizar o mundo a sua volta. Esse tipo de educação demanda a participação de todos os atores do contexto escolar no sentido de discutir os seus objetivos em relação a um projeto educativo que abarque as questões do dia a dia da sociedade relacionadas ao uso de drogas. Por meio da gestão democrática, cada comunidade politicamente organizada deve participar ativamente da construção do projeto político pedagógico das suas escolas, para que possam servir às necessidades da sua própria comunidade e refletir criticamente sobre a sua história e realidade (Chagas e Pedroza, 2013).

Dessa forma, com base em um compromisso ético-político com a contribuição para políticas públicas de educação (Sousa, Pedroza e Sousa, 2014) envolvendo a temática do uso indevido de drogas, nosso objetivo é oferecer um espaço de escuta para que essas professoras possam avaliar o curso e seu material didático a fim de problematizar essas questões com seus alunos desde os anos iniciais de escolarização.

Entendemos, pois, que a construção de uma consciência crítica é um processo complexo que envolve inúmeros elementos, os quais ganham destaque durante as interações promovidas pelo contexto social, especificamente na escola. Porque nela se concentra uma parcela da população infantil e juvenil, que torna a escola um espaço privilegiado para a implementação de projetos pedagógicos preventivos (Moreira, 2006).

Atualmente, de acordo com as características de nossa sociedade, a escola se tornou, cada vez mais cedo, um ambiente, com o espaço familiar, importante para a interação, educação e formação da identidade social e pessoal das crianças. Está aí, portanto, nossa percepção de que a escola não pode ser considerada apenas um lugar de transição, de passagem, com um destino pré-determinado, em que as crianças se inserem para se tornarem adultos, futuros cidadãos (Moreira, 2006). 
Nossas crianças já são cidadãs de direitos e desejos com responsabilidades e possibilidades que contribuem para a sociedade (Sousa, Pedroza e Sousa, 2014). Diante disso, defendemos que na escola é possível dialogar com as crianças sobre questões que envolvam o tema da relação entre as pessoas, os deveres e direitos de cada um e de todos e problematizar questões que elas mesmas tragam para a discussão, e aquelas que estão postas pela mídia, pela literatura infantojuvenil, como os problemas contemporâneos com que nos deparamos no cotidiano. Eventualmente, as crianças podem levantar questões sobre a criminalidade ou as drogas (Tavares de Lima, 2011).

Nesse sentido, torna-se relevante a formação do professor do ensino fundamental voltada não apenas a aspectos profissionais, mas também pessoais, que possibilite o desenvolvimento do indivíduo, particularmente da personalidade do aluno e do professor. Pois, ao exercer sua prática docente pela transmissão de conhecimentos, desempenha também a função de educador de forma integral. A formação de professores, portanto, precisa contemplar sua atuação como mediador entre o conhecimento e o estudante, transformando ideias pedagógicas em ações concretas (Pedroza, 2014).

\section{MÉTODO}

Esta pesquisa é de caráter qualitativo, baseada na concepção de fazer científico que contempla a especificidade dos contextos da pesquisa, a singularidade dos participantes e a subjetividade do pesquisador (González-Rey, 2002). Entendemos, portanto, que não há separação entre sujeito e objeto de pesquisa, mas sim uma relação entre sujeitos, considerando o pesquisador e os participantes da pesquisa.

De acordo com Bogdan e Biklen (1994), na investigação qualitativa existe uma preocupação em contextualizar a pesquisa e analisar as informações, respeitando a forma que foram registradas. Há também um interesse maior pelo processo da pesquisa do que pelo resultado ou produto final, já que o "processo de condução de investigação qualitativa reflete uma espécie de diálogo entre os investigadores e os respectivos sujeitos, dado estes não serem abordados por aqueles de uma forma neutra" (Bogdan e Biklen, 1994, p. 51).

O objetivo de uma investigação qualitativa é compreender as relações e as experiências humanas, por meio da maneira com a qual as pessoas constroem seus sentidos, significados e os descrevem. A pesquisa qualitativa é, dessa forma, um processo de produção de conhecimento permanente, pois, durante seu desenvolver, novas questões podem surgir e indicar um novo caminho, implicando uma postura flexível do pesquisador. A intenção é realizar um fazer metodológico que considere a experiência e a curiosidade do pesquisador no encontro com seu objeto de pesquisa, estabelecendo um diálogo com os sujeitos pesquisados de forma interativa, motivada e intencional (González-Rey, 2002).

\section{PARTICIPANTES}

Participaram desta pesquisa vinte e uma professoras ex-cursistas da quinta edição do curso de prevenção ao uso de drogas para educadores de escolas públicas 
que atuam nos anos iniciais do ensino fundamental de diferentes regiões administrativas do Distrito Federal.

As entrevistadas foram escolhidas a partir de sua participação no curso de prevenção ao uso de drogas oferecido pela UnB/SENAD/MEC e de sua atuação nos anos iniciais do ensino fundamental em escolas públicas do Distrito Federal. A disponibilidade para contribuir com o estudo em questão foi fundamental para definir as participantes.

As professoras que aceitaram participar da pesquisa tinham entre $34 \mathrm{e}$ 65 anos quando fizeram o curso. Quatro professoras davam aula para o $2^{\circ}$ ano, duas para $04^{\circ}$ ano e duas para o $5^{\circ}$ ano. Três delas trabalhavam em classes especiais. Além disso, quatro ocupavam cargo na direção da escola e duas eram orientadoras pedagógicas. Quatro professoras lecionavam em diversos anos, do $3^{\circ}$ ao $9^{\circ}$ ano, não assumindo uma única turma em específico.

\section{INSTRUMENTOS E MATERIAIS}

Para a pesquisa foram utilizados gravador digital de voz e roteiro de entrevista semiestruturada, elaborado pelos pesquisadores valendo-se do objetivo da pesquisa. O roteiro foi composto de questões que buscavam levantar, inicialmente, informações sobre a formação e atuação das professoras na escola e no magistério. Em seguida, buscou compreender seu interesse sobre a participação no curso, assim como suas opiniões sobre o conteúdo e sua aplicabilidade no cotidiano da escola. No decorrer da entrevista, o roteiro foi sendo direcionado para questionamentos sobre uso de drogas na escola e sobre como ocorriam suas intervenções nesses casos. Além disso, foram feitas perguntas sobre a autonomia e interesse das professoras em abordar a temática de drogas dentro de sala de aula. Ao final, as questões giraram em torno da relação das famílias com as atividades da escola, inclusive as que envolviam o assunto de uso de drogas.

\section{PROCEDIMENTOS}

Após a aprovação do Comitê de Ética em Pesquisa com Seres Humanos, foi apresentado o convite às professoras da Secretaria de Educação do Distrito Federal para participar da pesquisa. A partir disso, foi solicitada a assinatura do Termo de Consentimento Livre e Esclarecido. Realizamos, posteriormente, entrevistas de acordo com a disponibilidade das participantes, registrando as informações por meio de gravador digital de voz.

Por fim, as entrevistas foram transcritas e categorias foram construídas com base na frequência das respostas das professoras, das questões levantadas no roteiro e da relevância para o objetivo do estudo. Esse processo realizou-se inspirado pela análise de conteúdo proposta por Bardin (1977). Inicialmente organizamos as informações, a fim de sistematizar as ideias trazidas pelas professoras. Os temas foram classificados seguindo o roteiro de entrevista e as inferências e interpretações dos pesquisadores.

Ressaltamos, ademais, que nesta pesquisa a análise do momento empírico está relacionada com uma reflexão crítica, apontando a importância de se estabelecer um diálogo entre a fundamentação teórica e a análise desse momento. 


\section{RESULTADOS E DISCUSSÃO}

Tomando como base os objetivos desta pesquisa, das falas das vinte e uma professoras entrevistadas e da análise realizada, foi possível criar as seguintes categorias temáticas:

1. Percepção das professoras sobre o contato das crianças com drogas e o acolhimento do tema na escola;

2. Concepções das professoras sobre sua prática pedagógica;

3. Relação família-escola;

4. Percepções sobre o curso realizado e sugestões para as próximas edições.

Adiante, apresentaremos as análises dessas categorias, fazendo uma articulação com a fundamentação teórica desta pesquisa.

\section{PERCEPÇÃO DAS PROFESSORAS SOBRE O CONTATO DAS CRIANÇAS COM DROGAS E O ACOLHIMENTO DO TEMA NA ESCOLA}

Nessa categoria, foram reunidos os relatos das professoras, com base em sua experiência docente, concernentes às suas percepções acerca do contato e das vivências que as crianças demonstram ter com as drogas diretamente ou com essa temática de maneira geral. Essa categoria traz, portanto, elementos importantes para nossa discussão, uma vez que a relação das crianças com as drogas não tem sido muito abordada em pesquisas da área, mais voltadas para a adolescência e juventude (Moreira, 2010), apesar de levantamentos mostrarem que o consumo de drogas existe nessa faixa etária (Carlini et al., 2010). Além disso, são trazidas as reflexões das entrevistadas acerca da possibilidade de trabalhar a temática das drogas com os estudantes de idade pequena.

Quando questionadas sobre se acreditam que as crianças de sua escola têm contato com drogas, a maioria das entrevistadas afirmou que esse contato existe fora do espaço escolar, indiretamente, por meio de familiares ou da comunidade onde moram. Esse discurso é apresentado, por exemplo, nas falas de duas professoras: "o cigarro e a bebida é algo comum, as crianças veem o pai fazendo, a mãe fazendo, aí eles acabam fazendo também"; e "as crianças têm contato com as drogas, não de usarem, mas de vivenciarem. Pais que se envolvem com drogas ou drogas na comunidade".

Seguindo essa compreensão, algumas professoras relataram que a temática das drogas pode e deve ser abordada com crianças da idade com que trabalham. No entanto, veem essa intervenção como um desafio e enfatizam ser necessário cuidar da forma como se aborda o assunto. Vimos anteriormente, com Masschelein e Simons (2013) e Camarotti, Kornblit e Di Leo (2013), a necessidade de a escola estar mais preparada para acolher temas como esse, que já fazem parte do cotidiano das crianças.

Em contrapartida, algumas entrevistadas acreditam que a escola não possui a função de assumir essa demanda, pois "a responsabilidade é dos pais. A escola pode ajudar em relação às amizades, mas a escola já tem muita coisa para fazer e não aguenta se responsabilizar por mais essa". Outro argumento utilizado pelas profes- 
soras se sustenta na percepção de que a droga "está fora da escola", ou seja, não há um contato direto dentro dela, então não caberia à escola acolher essa demanda. No entanto, acreditamos que, se as crianças falam sobre as drogas, como foi afirmado pelas professoras, isso pode significar que as drogas podem fazer parte do cotidiano delas. Mesmo que seja apenas por meio dos familiares e da comunidade onde vivem, a escola precisa se posicionar em relação a isso e acolher o que os alunos trazem.

Essa questão demonstra a falta de flexibilidade do planejamento de aulas e dos currículos escolares no ensino tradicional, que precisam ser abertos para o que é vivido em sala de aula e no cotidiano da escola (Corsi e Lima, 2010). A necessidade de se trabalhar a temática das drogas com as crianças de modo que possa acolher suas reflexões e vivências demanda essa flexibilidade. Estruturas curriculares rígidas assemelham-se ao que Vigotski (2004) apontava desde o início do século passado acerca do professor gramofone, ou seja, quando esse profissional é tão repetitivo e estático em seu fazer que pode facilmente ser substituído por um gravador de voz contendo suas aulas anteriores.

Além disso, o autor ressalta a importância de romper os muros da escola para aproximar a vida da sala de aula. O currículo escolar precisa estar direcionado à construção do conhecimento para as necessidades das transformações da sociedade. Para isso, os valores, ética e anseios da comunidade devem ser abordados em todos os momentos vividos na escola. Dessa forma, a escola deixaria de tratar dessas questões apenas nas ditas "Semana da Vida", "Semana dos Valores", como visto na fala de uma professora sobre o planejamento das atividades de sala de aula: "a gente tem os temas amplos e assim entra a questão das drogas. Em maio temos a semana de valorização da vida, onde aproveitamos para falar desses temas difíceis, digamos assim". Defendemos, a partir de Vigotski (2004), que as questões da vida cotidiana não devem estar dissociadas da sala de aula. As questões como valores, ética, direitos humanos, entre outros, podem ser discutidas a todo momento. Essas questões precisam ser vividas nas relações sociais no cotidiano da escola para realmente se efetivarem enquanto processo educativo que promove o desenvolvimento de todos os membros da escola (Chagas e Pedroza, 2013).

As entrevistas demonstram uma contradição na maneira como as professoras abordam essas questões. Ao mesmo tempo em que a maioria afirma que o contato dos alunos com as drogas não acontece na escola, algumas relatam fatos isolados que escancaram o uso de drogas dentro dela. Uma comentou que um aluno de 12 anos foi pego fumando e bebendo dentro do banheiro da escola. Outra professora relatou o fato de um aluno comentar que havia um colega que usava maconha na escola. Nesse episódio, a educadora orientou que o aluno não experimentasse a droga, por acreditar que tal experimentação é "uma porta aberta para outras drogas".

Uma entrevistada discorreu sobre o acontecimento em que um aluno assassinou um jovem traficante, estudante da mesma escola, quando este foi cobrar uma dívida de tráfico do irmão, e posteriormente cometeu suicídio. Na referida situação, a professora declarou que levou o assunto para seus alunos, os quais sinalizaram já ter conhecimento sobre as drogas.

Com isso, questionamos qual seria o papel do educador ao se deparar com cenas como essas. Entendemos que é importante as professoras escutarem e busca- 
rem compreender os sentidos das falas de cada criança, acolhendo suas demandas. Um exemplo disso pode ser visto na fala de uma professora, quando narra que um estudante trouxe vinho para a escola. Ela contou que, nessa ocasião, realizou "em sala uma roda de conversa para comentarem o que aconteceu. Aí, os outros contaram que já experimentaram. Eles trouxeram vivências das famílias, de pai bêbado. Viam rapazes fumando maconha do lado da escola e eles já reconheciam o cheiro”.

Esse episódio demonstra como é possível, a partir de uma situação inesperada, desenvolver uma prática educativa com sentido e sem imposição para as crianças, valorizando suas opiniões e experiências. Situações como essa podem, até mesmo, gerar projetos pedagógicos em que as próprias crianças se envolvem ativamente na construção da prática educativa. É possível realizar pesquisas sobre a sua realidade com vistas a ampliá-la ao entrar em contato com conhecimentos técnico-científicos e informações essenciais para a construção da sua autonomia perante o uso de drogas (Albertani, Scivoletto e Zemel, 2014).

Notamos ainda que algumas professoras apontaram as drogas como um assunto emergente nas falas e manifestações das crianças no cotidiano escolar, o que pode ser percebido nesta afirmação: "as crianças falam entre si das drogas e, quando os professores falam do assunto, elas se posicionam...”. Mais uma vez, reafirma-se a necessidade de conceber as drogas como parte da realidade das crianças e que a escola é um lugar de acolhimento às experiências e histórias trazidas por elas.

Desse modo, consideramos que é fundamental reconhecer e valorizar o conhecimento que a criança traz para o contexto da escola como base para qualquer prática pedagógica, mesmo aquelas que envolvam assuntos tão complexos como o uso indevido de drogas. Esse aspecto fica claro nas próprias afirmações das professoras, que reconhecem essa necessidade, dado que todas as crianças têm uma história anterior à entrada na educação formal.

Para tanto, entendemos que são necessários estratégias e materiais didáticos construídos de maneira reflexiva e crítica que possam auxiliar as professoras em sua prática cotidiana. Isso justifica a realização de pesquisas que compreendam as concepções das professoras sobre o tema das drogas, visando à elaboração de materiais que partam de seus conhecimentos, suas experiências, questionamentos, desafios e necessidades quanto à sua prática pedagógica para abordar a questão das drogas em sala de aula.

Ademais, mesmo considerando um desafio, as professoras apresentaram diversas possibilidades para se trabalhar o tema das drogas com as crianças. Uma das entrevistadas trouxe a possibilidade de trabalhar essa temática a partir das manifestações das próprias crianças. Ela declarou que sua "forma de trabalhar não é 'a droga é isso ou aquilo'. Se acontecer algo, aí eu sento, converso, falo sobre os prejuízos. Mas eu não chego e falo 'olha, hoje vamos falar sobre drogas'. [...] Eu trabalho a valorização deles mesmos, da vida”. Em contrapartida, apareceu a afirmação de que a questão das drogas deve ser apresentada sem muito aprofundamento, sendo mais adequado falar sobre isso a partir do $5^{\circ}$ ano, com crianças em torno de 10 anos, embora não apresente uma justificativa para tal ação.

Em entrevista feita com professoras que lecionam exclusivamente para alunos com necessidades especiais, foi destacada sua preocupação em protegê-los, alegando 
que eles são "presas fáceis" para o tráfico de drogas. Além disso, afirmam acreditar que não seja possível falar sobre drogas com estudantes com necessidades especiais e que "não há muito que aprofundar, senão a gente acaba atrapalhando e não ajudando", "o que se comenta é para não aceitarem o que os desconhecidos oferecem". Ao mesmo tempo, outras defendem a possibilidade de se abordar esse tema mesmo com os "alunos especiais, desde que o vocabulário seja adequado".

Uma das entrevistadas disse que busca trabalhar com uma postura de proximidade aos alunos, pois dessa forma é mais fácil descobrir se eles têm algum "problema relacionado a familiares que usam drogas ou outro tipo de problema". Então ela intervém pela via da amizade e da confiança, para se aproximar das crianças. Além disso, acrescentou que, quando algum aluno apresenta uma situação de seu cotidiano, faz um atendimento individual. Demonstra, portanto, a visão de que não há espaço em sala de aula para essas questões, que deveriam ser abordadas no coletivo da turma como parte do trabalho pedagógico. Esse atendimento individual fica claro na fala de outra professora, que relatou acreditar que no decorrer de sua experiência na escola desenvolveu a capacidade e a competência de perceber o aluno em seu todo, acolhendo sua história de vida e reconhecendo suas dificuldades advindas de experiências familiares ruins.

Há ainda professoras que afirmam ser impossível conversar sobre drogas com seus alunos, pois não encontram como "resolver o problema", sendo assim, a melhor solução seria evitar o assunto. Nesse sentido, consideramos mais uma vez a importância de um curso voltado para professoras dos anos iniciais do ensino fundamental, construído no diálogo e na reflexão sobre como acolher o que os estudantes trazem para a escola. Da mesma forma que entendemos que seja essencial que as professoras escutem seus alunos, também valorizamos e reconhecemos a necessidade de escutar e acolher as professoras.

Os relatos das professoras englobados nessa categoria nos permitem reafirmar, portanto, que uma prática educativa de qualidade voltada para a construção da cidadania precisa levar em consideração a temática das drogas, entre outras questões, que seja pautada no acolhimento das vivências de cada criança e na interlocução diária entre os fatos relevantes que acontecem dentro e fora da escola.

\section{CONCEPÇÕES DAS PROFESSORAS SOBRE SUA PRÁTICA PEDAGÓGICA}

A segunda categoria engloba as reflexões trazidas pelas professoras acerca de sua prática pedagógica e sua função diante dos alunos. Com base nas entrevistas, foi possível perceber que a maioria das professoras entende que seu papel é como educadora e cada uma se relaciona de forma particular com seus alunos. Algumas afirmam que tratam seus alunos como se fossem filhos, o que nos faz indagar se essas professoras reconhecem que sua prática pedagógica envolve também a formação da personalidade do aluno, conforme ressaltado por Pedroza (2014).

Essa concepção como educadora pode ser exemplificada pela fala de uma professora: "minha função é muito mais do que ser professora, não é só transmitir conhecimento, mas, sim, ser educadora, estar preparando os alunos para a vida, para serem melhores cidadãos". Outras consideram, ainda, que não têm uma função, mas sim uma missão, ao servir de "modelo de identificação"; "trabalhar o ser pessoa, 
ser do bem, realizar um sonho, ajudar e ser útil ao outro, ser um cidadão, deixar que a sociedade fique melhor. E, para isso, precisamos de conhecimento".

Evidenciamos, pela fala das professoras, que há uma valorização da profissão por elas mesmas, ao definir, por exemplo, sua prática pedagógica como "um aprender e ensinar. Formação que vai para a vida toda"; "tem contribuição na vida das crianças. O professor marca a vida da criança. Tem papel crucial na formação”. Outras acrescentaram que sentem que o professor tem um papel muito importante na sociedade.

Podemos notar que tais professoras se percebem como figuras importantes na formação de seus alunos, atribuindo uma relevância à sua função para além das fronteiras da escola, envolvendo-se mais com os alunos, chegando a fazer até um pouco o papel que deveria ser da família. Essa percepção é evidenciada na fala de uma professora do ensino especial: "nosso papel é até meio confundido com o papel como cuidador. Mas eu vejo que eu estou aqui preparando as crianças para a vida lá fora".

Em um dos espaços investigados, o qual atende exclusivamente pessoas com necessidades especiais, a orientadora educacional diz que seu trabalho é um pouco diferente. Relata que, como não tem assistente social na escola, acaba assumindo esse papel para garantir o cuidado e o bem-estar de seus alunos. Também revela fazer um trabalho de aproximação da escola com os pais.

Pelas respostas dadas nas entrevistas, podemos pensar que a pergunta sobre a função desempenhada pelas professoras foi entendida mais em relação às atividades complementares da sala de aula do que uma reflexão sobre a própria prática pedagógica. Isso pode ser evidenciado pelas falas das professoras, que se remeteram a ações de cuidado, valorizando sua profissão apenas como uma dedicação pessoal, sem uma visão crítica da sua responsabilidade como profissional da educação que também deve desempenhar a função de mediador do conhecimento socialmente construído.

\section{RELAÇÃO FAMÍLIA-ESCOLA}

Essa categoria engloba relatos das professoras acerca da sua percepção quanto à relação família-escola. De maneira geral, as falas das entrevistadas evidenciaram os desafios para aproximar a escola dos pais de seus alunos e suas tentativas nesse sentido. Essa importância foi ressaltada na fala de uma professora a respeito da relevância do professor saber ouvir seus alunos, pois ela tem um importante papel na relação com os pais ao contribuir em um cuidado adequado de seus filhos. Do mesmo modo, outra professora percebe que os pais também entendem que o educador é uma referência para ajudar na criação dos alunos. Dessa maneira, a escola deve apoiar a família e não a substituir (Pedroza, 2003).

Notamos, porém, que, por mais que as professoras tenham um reconhecimento da importância dessa relação família-escola, ainda há um conflito sobre seus papéis. Para uma das entrevistadas, caberia à escola "reforçar e orientar o que eles [os alunos] aprendem em casa. Estamos numa época que ficamos com muitas tarefas, por vezes coisas que não nos cabe. Às vezes até um ouvir. Só de ouvir ele já alivia. Sente-se mais que uma professora, até mesmo uma mãe".

Além disso, percebemos que às vezes há um incômodo no modo como essa interação acontece, o que pode ser visto no discurso de uma das professoras: 
"antigamente, os pais tinham mais responsabilidade. Existia mais a palavra respeito. Hoje, os pais se acham no direito de vir, colocar o dedo no nariz da gente. Cobram demais e muitos não fazem a parte deles".

Destacamos, com isso, a concepção das professoras sobre a importância de uma aproximação entre a família e a escola como parte de sua prática pedagógica, pois escola e família devem ser consideradas continuidade uma da outra, em parceria, reconhecendo os papéis e funções de cada segmento (Brillinger e Sudbrack, 2014). Portanto, ambas não podem ser vistas como momentos de oposição ou de disputa para ver quem é a maior responsável pela educação das crianças. São instituições diferentes e necessárias na constituição do sujeito (Pedroza, 2003).

Algumas professoras, mesmo que procurem criar uma relação tranquila com a família de seus alunos, se deparam com alguns entraves. Uma delas afirmou que essa relação é restrita às reuniões de pais e mestres e às atividades festivas da escola. Outra contou que, em sua turma, tem um contato diário com as famílias e que na escola, a cada quinze dias, reserva um horário para os pais de alunos que estão dando muito "problema". Ela ainda se queixou que são poucos os que participam dessas reuniões e que, normalmente, buscam os professores apenas quando acontece algum tipo de "problema". Percebe-se em pesquisas sobre a relação família-escola (Silveira e Wagner, 2012; Varani e Silva, 2010) que essas são situações comuns nas escolas brasileiras, sendo necessário trabalhar no intuito de agregar essas instituições (família e escola) a fim de promover o desenvolvimento integral dos estudantes e melhorar a qualidade de vida de todos os membros da escola.

Uma das professoras disse que tem um contato muito bom com a família de seus alunos, definindo-o como uma relação de amizade. No entanto, percebemos que muitas vezes a tentativa de ajudar a família passa pela sua desautorização, quando se assume o papel que é dela. Essa situação pode ser evidenciada na fala da professora quando ela conta que certa vez tinha um aluno muito pobre que teria de faltar duas semanas de aula por não ter dinheiro. Então relatou que "duas mães de outros alunos acolheram esta criança; ela ficou na casa delas até o recesso aqui da escola. Depois conseguimos até um emprego para a mãe deste aluno mais pobre”. Essa ação, que poderia ser vista como solidária, também pode ser considerada assistencialista, que extrapola os limites da relação família-escola e não contribui com o fortalecimento das condições da própria família (Bhering e De Nez, 2002).

De forma semelhante, umas das entrevistadas relatou que tem um contato diário com os pais que levam as crianças à escola. Disse ainda que cada pai tem direito de agendar um atendimento com o diretor ou com o professor quando achar necessário ou a pedido da escola, além das reuniões bimestrais e dos dias temáticos. Ela acrescentou que os pais são bastante participativos, o que parece ser diferente do que foi afirmado pela outra professora.

Uma questão recorrente nas entrevistas foi a dificuldade dos pais em comparecer com frequência à escola em virtude da carga horária no trabalho, o que leva algumas professoras a questionarem o comprometimento com a educação de seus filhos: "vimos que muitos pais não querem ter responsabilidade para com os filhos. A maioria não participa da vida da escola. Se preocupam com o trabalho. Os pais não têm tempo para os filhos e, assim, sobra para escola. O que reflete na escola o 
comportamento dos filhos". Como um modo de se aproximar desses pais, uma das professoras afirmou buscar realizar eventos com café da manhã, por ser um atrativo, e também enviar questionários para que eles possam avaliar a escola.

Nesse sentido, tenta criar alternativas que auxiliem a participação dos familiares dos estudantes nas atividades da escola: "os pais não vêm nas atividades da escola por não ter dinheiro para o transporte. Assim, combinamos com os motoristas dos transportes escolares que os trouxessem também juntamente com seus filhos em ocasiões de eventos". Dessa forma, a escola tenta uma aproximação com os pais nas reuniões pedagógicas bimestrais e em eventos festivos. No entanto, afirmou que nem todos correspondem aos convites escolares, acreditando que "no máximo 70\%" vão às festas promovidas pela instituição. Essa professora ainda faz uma observação dizendo que "os pais mais participantes em relação à escola têm filhos também mais participativos como alunos", e com os mais ausentes ocorre o contrário.

Essa mesma questão foi pesquisada por Varani e Silva (2010) na tentativa de compreender a influência da relação família-escola sobre o desenvolvimento de crianças dos anos iniciais do ensino fundamental. Nesse estudo, as pesquisadoras afirmam não ser possível justificar o desempenho escolar dos alunos somente pela presença ou ausência da família na escola. Apontam a necessidade de compreender que o fracasso ou o sucesso escolar constroem-se de maneira complexa, sendo necessário considerar fatores sociais, políticos, econômicos e culturais.

Uma entrevistada apontou que busca se aproximar e ter um relacionamento tranquilo com as famílias, pois acredita ser importante conhecer a realidade delas. Em suas palavras: "algumas pessoas pensam que só chamamos para a escola a família daqueles que têm problema, mas eu tento fazer diferente. Eu pergunto para a família como eu posso ajudar e como eles podem me ajudar. Trabalhar em parceria”. A fala de outra professora aponta para uma concepção semelhante, ressaltando a necessidade de parceria família-escola: "ano passado foi mais difícil, questão de limite, se não tem limite em casa fica difícil. Falta de limites dentro da família". Silveira e Wagner (2012) problematizam essa questão, enfatizando que muitas vezes a postura de culpabilização dos pais pelos professores reflete uma tentativa de diminuição da própria responsabilidade da escola nesse processo. Dessa forma, essas autoras destacam a necessidade de valorizar a parceria família-escola para promover o desenvolvimento das crianças.

Percebe-se, com base nas entrevistas, que as professoras compreendem a relação família-escola de maneira diversa e muitas vezes contraditória. A esse respeito, Brillinger e Sudbrack (2014) afirmam que, apesar de verem as famílias como possíveis parceiras em seu trabalho, os professores não costumam transformar esse reconhecimento em ação. Eles afirmam tentar aproximar a escola das famílias, questionam dissonâncias entre a educação familiar e a escolar e demonstram frustração quanto ao fato de que os pais, no final, parecem apenas se importar com notas e aprovação. Dessa forma, as autoras entendem que a família tem um importante papel na melhoria do trabalho escolar e que, mesmo quando essas duas instituições não estão em consonância, podem oferecer aos estudantes criatividade no enfrentamento do cotidiano, desde que essas diferenças sejam percebidas como parte da diversidade. 
$\mathrm{Na}$ discussão sobre a relação escola-família, algumas professoras entraram, ainda, no tema das drogas e de como os familiares percebem as possibilidades de trabalho nessa temática com as crianças. Uma das entrevistadas afirmou que "não houve demanda dos pais, nem contra, nem a favor, dos temas das drogas, apenas sobre sexualidade que eles acham ruim". Disse ainda que "a dúvida sobre droga brota das vivências dos alunos e aí vou construindo as discussões. Eu não exponho as famílias quando são questionadas, mas às vezes trago no próprio cotidiano". Outra professora afirmou que "os pais pedem para trabalhar alguns temas. Mas nunca pediram para trabalhar o tema drogas". Essas falas demonstram que essa temática não parece estar muito presente no diálogo das professoras com os pais dos estudantes.

\section{PERCEPÇÕES SOBRE O CURSO REALIZADO E SUGESTÕES PARA AS PRÓXIMAS EDIÇÕES}

$\mathrm{Na}$ quarta categoria, serão apresentadas as percepções das educadoras sobre o curso realizado, apontando sugestões para as próximas edições. Primeiramente, retomamos os motivos que levaram as professoras a realizarem a quinta edição do curso de prevenção ao uso de drogas. As entrevistadas afirmaram que os motivos foram diversos, sobressaindo o reconhecimento da UnB como uma instituição séria, o interesse pelo tema abordado e a valorização para o currículo delas. Ademais, o fato de reconhecerem que as drogas fazem parte da realidade dos alunos e a existência de um projeto de saúde e prevenção na escola foram fatores motivadores para a realização do curso. Uma professora, em específico, decidiu fazer o curso por já ter trabalhado no ensino médio, porém acreditava que na atual escola os alunos dos anos iniciais do ensino fundamental "não têm tanto contato com droga, a não ser pelos medicamentos".

Problematizamos, a partir disso, o uso dos medicamentos nas escolas como um uso de drogas nesse espaço. De acordo com Decotelli, Boher e Bicalho (2013, p. 453), a lógica de proteção aos alunos tem sido usada como uma justificativa para a intervenção médica em instituições familiares e escolares: "Passou-se a buscar uma educação para a criança com o fim de criar o adulto adequado à ordem médica”. Os autores afirmam que cabe à psicologia, como uma área de conhecimento, reconhecer as vivências e saberes fora da instituição, legitimando-os e revelando uma outra face da escola, a de ser "o lugar de encontro, antes de ser o lugar da disciplina por excelência, o lugar de fazer ver o que a criança ensina” (Decotelli, Boher e Bicalho, 2013, p. 458).

Enfatizamos a necessidade de as professoras estarem disponíveis a escutar aquilo que vem da criança, acolhendo-a e aprendendo com ela, inclusive no que tange ao uso de drogas, mesmo sendo algo desafiador, como exemplificado na seguinte fala: "é um desafio, porque as crianças trazem relatos espontâneos das coisas que vivenciam. Por trás das perguntas delas, tem uma curiosidade sobre o tema”. Outra professora aponta que um dos caminhos para tornar possível esse diálogo espontâneo é por meio do brincar, pois, "quando brincava e interagia com os alunos, eles achavam que eu era uma amiga e, dessa forma, falavam naturalmente sobre as percepções delas acerca de drogas". Outra entrevistada ressaltou como o curso foi relevante para a reflexão de sua prática pedagógica ao afirmar que agora "escuta mais as crianças", procurando entender o porquê de determinadas situações que são trazidas para a escola. 
Ressaltamos a importância da realização do curso de prevenção ao uso de drogas, uma vez que as professoras afirmaram que a partir dele sua concepção sobre drogas se transformou, ampliando a compreensão delas sobre o tema. Uma entrevistada relatou que a droga vai além do que é ilícito, definindo-a como "tudo aquilo que altera o seu normal". Outra disse que "não podemos pensar só nas drogas lícitas e ilícitas. Na nossa vida, podemos estar criando algumas outras drogas". Uma terceira destacou ainda que o curso apresentou "uma concepção abrangente, trazendo conceitos sobre drogas lícitas e ilícitas [...] o cafezinho em nossa sociedade, a cerveja do final de semana, muitas crianças cujos pais fumam...”.

Essas falas demonstram que o curso permitiu às professoras o contato com uma concepção diferente em relação ao uso de drogas, conforme a sua intenção, que aponta para uma compreensão do sentido que a droga pode ganhar na vida de cada pessoa e na sociedade de maneira geral. Foca-se mais na promoção da saúde do que na repressão ao uso de drogas (Sudbrack, 2014). Atualmente, a condenação ao uso de drogas e as políticas de repressão implementadas há anos em vários países têm sido questionadas em sua ineficácia, apontando a importância de melhores condições de vida para as pessoas como algo muito mais fundamental para o processo educativo relativo às drogas (Paula et al., 2014).

Durante as entrevistas, algumas professoras, ao demonstrarem satisfação com a concepção de drogas abordada no curso, deixaram de falar sobre as suas próprias ideias em relação à temática. No entanto, disseram que o tema foi bem trabalhado e apresentado de forma atrativa, o que pode ser percebido em algumas falas, como: "o curso foi bom para abrir nossa visão em relação a isto, no sentido de trabalhar com a família"; "o curso ajudou na maneira de conversar com os alunos". Algumas delas relataram que gostaram dos vídeos apresentados durante o curso, pelo fato de tê-las inspirado a trabalhar e conversar com os alunos sobre diversos temas, mesmo aqueles que são difíceis de serem discutidos. Esses comentários evidenciam a necessidade da elaboração de materiais audiovisuais que possam inspirar da mesma forma uma atuação com as crianças.

Outras professoras apresentaram concepções diferentes sobre as drogas, afirmando que o conteúdo abarcado no curso se refere a uma abordagem "mais moderna". Elas ressaltaram que "não é possível acompanhar a rapidez com que as novas drogas aparecem e os adolescentes têm acesso". Essas professoras afirmaram que os jovens têm contato mais abrangente e mais rápido com o universo das drogas, para além daquilo que foi mostrado no curso, o que acaba dificultando o trabalho delas. Dessa forma, demonstram certa resistência à abordagem apresentada no curso.

Ferreira et al. (2010) destacam que professores, mesmo sendo conhecedores da importância da prevenção às drogas, têm demonstrado resistência em trabalhar tal temática em sala de aula e por vezes consideram a possibilidade de recorrer a outros profissionais, especializados, para essa incumbência.

Entretanto, ressaltamos que a maioria das professoras se mostrou aberta e disponível para trabalhar o assunto das drogas em sala de aula. $O$ fato de elas terem feito o curso pode ter ajudado a construir essa postura mais disposta a acolher aquilo que vem do outro e a debater temas mais difíceis e considerados tabus na nossa sociedade. Retomamos que a escola é um espaço que vai além da transmissão de saberes, sendo 
os educadores sujeitos fundamentais ao acolhimento de diversos conteúdos que emergem por parte dos alunos. Esse ambiente pode tornar-se propício ao desenvolvimento de recursos de personalidade e ações de promoção de saúde (Sudbrack e Dalbosco, 2005).

Silva (2011) enfatiza que a assimilação de novos conhecimentos e a busca de novas práticas pedagógicas contribuem de forma positiva, bem como revigoram a confiança do profissional. Considera, ainda, a capacitação de educadores uma estratégia de prevenção na escola que traz novas possibilidades para sua prática e favorece a valorização da função educativa.

No estudo de Soares e Jacobi (2000) é destacado que os educadores têm convicção da importância da capacitação para mobilizar reflexões de temas sobre processos que envolvem a relação do indivíduo com as drogas, pois no espaço escolar ainda são percebidas certas ideias preconcebidas que dificultam a abordagem do tema.

Além disso, as professoras destacaram que o conteúdo abordado no curso superou as suas expectativas, discorrendo sobre temas que elas "nem imaginavam", o que não era "necessariamente, só sobre drogas". Outra professora ainda destacou que "gostou do conceito de drogas e que [ele] não deve ser proibitivo [...] é possível abordar o tema drogas com crianças de 6,7 anos". Novamente, essas falas demonstram a apresentação da concepção de drogas pelo curso, com foco na promoção da saúde, e não na condenação ao seu uso (Sudbrack, 2014), rompendo com um discurso de repressão ao uso de drogas, apontando para outros possíveis caminhos (Decotelli, Boher e Bicalho, 2013; Paula et al., 2014), ou seja, por uma educação que promova a construção de possibilidades de autonomia do sujeito sobre seu corpo e sua saúde.

A partir das entrevistas com as professoras, notamos que o assunto das drogas tem certa liberdade de ser trabalhado na escola quando surge o interesse das professoras, considerando que muitas delas afirmam existir uma autonomia, até mesmo na construção do planejamento curricular. Essa percepção é reforçada, por exemplo, quando uma entrevistada afirma que "o planejamento é feito de forma a dar liberdade dos professores intervirem" ao identificar uma situação que justifique essa ação. Outra professora ainda disse: "tenho autonomia sim. Como orientadora, tenho o planejamento maior ancorado no PPP e tenho também outros projetinhos mais rápidos, porque aqui tem que ser rápido, senão eles perdem a atenção".

Algumas professoras avaliaram que o curso deveria ter mais envolvimento com a prática pedagógica, destacando que sentiram falta de instrumentos para intervir nas situações exatas em que o uso das drogas está acontecendo. Elas manifestaram que o curso foi mais voltado para prevenção e poderia ter propostas mais práticas para situações em que os alunos já estão envolvidos com drogas. Outra professora ainda propôs uma parte inicial do curso englobando uma abordagem mais geral do assunto, para depois separar e fazer pequenos projetos mais específicos voltados para as faixas etárias com que cada professora trabalha, para sua aplicação na escola. Ainda disseram que é importante pensar em estratégias para "chegar nas famílias e fazer que os alunos se expressem mais".

As professoras sugeriram que houvesse mais textos direcionados aos professores dos anos iniciais do ensino fundamental, indicando vídeos e desenhos animados como boas estratégias de trabalho com as crianças e propondo "atividades práticas 
e até mesmo uma produção ao invés do relatório, para propor produção para os alunos e ver o que as crianças pensam, o que elas já viram lá fora. Vemos crianças de 8 anos saber o que é uma pedra de crack". Sugeriram também que haja espaço para as crianças realizarem suas próprias produções sobre o tema, permitindo que sejam apresentadas, por exemplo, em forma de oficinas.

Outras professoras deram diferentes propostas, como apresentar o projeto final pessoalmente, e não pela plataforma do curso, além de acharem que os professores conteudistas poderiam visitar as escolas ao longo do curso. Propuseram, ainda, que no futuro o curso visasse instrumentalizar melhor os professores, por meio de exemplo de práticas que permitam o acolhimento aos alunos que já estejam envolvidos com drogas, ou ter "uma palestra com alguém que tenha essa vivência", ou ainda "ter um material bem mais leve, mais sutil, com os mais novos, como meios que se deve trabalhar a questão das drogas lícitas para não incentivar a curiosidade das outras".

Com base nas discussões feitas nessa categoria, fica evidente a importância do curso para a prática educacional e quanto ele suscitou reflexões e sugestões para novas edições. E possível perceber, ainda, a demanda por um curso voltado para as questões mais específicas dos anos iniciais do ensino fundamental.

\section{CONSIDERAÇÕES FINAIS}

Esta pesquisa, além de alcançar o objetivo de levantar as concepções de professoras do ensino fundamental, dos anos iniciais, que participaram da quinta edição do curso mencionado, também permitiu uma reflexão sobre a prática cotidiana de cada professora e a necessidade do acolhimento às vivências e da escuta dos discursos das crianças sobre as drogas. Possibilitou, ainda, evidenciar a demanda das professoras de materiais didáticos e cooperação com pesquisadores da área a fim de construir condições de desenvolver um trabalho voltado especificamente para essa faixa etária.

Ressalta-se a importância da metodologia qualitativa desta pesquisa, na medida em que, ao se escutar cada entrevistada, abre-se a possibilidade de se conhecer o sentido subjetivo da experiência dessas educadoras diante do tema das drogas. Nessa perspectiva, a relação dos pesquisadores com as professoras proporcionou um processo que evidencia suas contradições, dúvidas, angústias e desejos de superar as dificuldades de lidar com questões delicadas e complexas presentes no cotidiano da escola.

Ao refletirem sobre a presença ou não das drogas nos anos iniciais, as professoras tomaram consciência de que há abertura para que elas abordem essas questões. No entanto, apresentaram a demanda de formação teórico-prática como instrumento que auxilie o seu trabalho pedagógico. Dessa forma, a pesquisa constituiu-se em uma oportunidade de se considerar a escola um lugar de encontro entre pessoas de gerações diferentes que não só se relacionam com a finalidade de aprendizagem de conteúdos cognitivos, mas desenvolvem, juntas, novas possibilidades de relacionamento de caráter afetivo e emocional. O espaço/tempo da escola propicia a construção de subjetividades que participam em comunidade, na qual todos se socializam no processo de humanização. 


\section{REFERÊNCIAS}

Ariès, P. História social da criança e da família. 2. ed. Rio de Janeiro: Livros Técnicos e Científicos, 1981.

Albertani, H. M. B.; Scivoletto, S.; Zemel, M. L. S. Trabalhando com prevenção na família, na escola e na comunidade. In: Brasil. Ministério da Justiça. Secretaria Nacional de Políticas sobre Drogas. Curso de prevenção do uso de drogas para educadores de escolas públicas. 6. ed. Brasília: SENAD/MJ, 2014. p. 135-151.

Bardin, L. Análise de conteúdo. Lisboa: Edições 70, 1977.

Bhering, E.; De Nez,T.B. Envolvimento de pais em creche: possibilidades e dificuldades de parceria. Psicologia: Teoria e Pesquisa, Brasilia: UnB, v. 18, n. 1, p. 63-73, abr. 2002.

BogdAn, R. C.; BikLen, S. K. Características da investigação qualitativa. In: BogdAn, R. C.; Biklen, S. K.(Orgs.). Investigação qualitativa em educação. Porto: Porto Editora, 1994.p. 47-51. Brillinger, N. S.; Sudbrack, M. F. O. Parceria escola-família na prevenção do uso de drogas: o olhar dos educadores. In: Brasil. Ministério da Justiça. Secretaria Nacional de Políticas sobre Drogas. Curso de prevenção do uso de drogas para educadores de escolas públicas. 6. ed. Brasília: SENAD/MJ, 2014. p. 246-249.

Camarotti, A. C.; Kornblit, A. L.; Di Leo, P. F. Prevención del consumo problemático de drogas en la escuela: estrategia de formación docente en Argentina utilizando TIC. Interface - Comunicação, Saúde, Educação, Botucatu: UNESP, v. 17, n. 46, p. 695-703, set. 2013.

CARLINI, E. L. A. et al. IV Levantamento nacional sobre o consumo de drogas psicotrópicas entre do ensino fundamental e médio das redes pública e privada de ensino nas 27 capitais brasileiras. São Paulo: CEBRID; UNIFESP; Brasília: SENAD/MJ, 2010.

Chagas, J. C.; Pedroza, R. L. S. Psicologia escolar e gestão democrática: atuação em escolas públicas de educação infantil. Psicologia Escolar e Educacional, Maringá: ABRAPEE, v. 17, n. 1, p. 35-43, jun. 2013.

Corsi, A. M.; Lima, E. F. Práticas pedagógicas no ensino fundamental na perspectiva do multiculturalismo crítico. Curriculo sem Fronteiras, [S.1.: s.n.]: v. 10, n. 2, p.158-182, jul./ dez. 2010. Disponível em: <http://www.curriculosemfronteiras.org/vol10iss2articles/ corsi-lima.pdf $>$. Acesso em: 30 jun. 2015.

Decotelli, K. M; Boher, L. C. T.; Bicalho, P. P. G. A droga da obediência: medicalização, infância e biopoder - notas sobre clínica e política. Psicologia: Ciência e Profissão, Brasília: CFP, v. 33, n. 2, p. 446-459, 2013.

Ferreira, T. C. D. et al. Percepções e atitudes de professores de escolas públicas e privadas perante o tema drogas. Interface Comunicação Saúde e Educação, Botucatu: UNESP, v. 14, n. 34, p. 551-562, set. 2010.

González-Rey, F. Pesquisa qualitativa: caminhos e desafios. São Paulo: Pioneira Thomson Learning, 2002.

Masschelein,J.; Simons, M. Em defesa da escola: uma questão pública. Belo Horizonte: Autêntica Editora, 2013. 
Moreira, F. Redução de danos do uso indevido de drogas no contexto da escola promotora de saúde. Revista Ciência e Saúde Coletiva, Rio de Janeiro: ABRASCO, v. 11, n. 3, p. 807-816, jul./set. 2006.

Moreira, L. A. Drogas e prevenção na infância: representações sociais de estudantes que vivenciaram o PROERD. 155f. Dissertação (Mestrado em Educação Tecnológica) - Centro Federal de Educação Tecnológica de Minas Gerais, Belo Horizonte, 2010.

Paula, M.L. et al. Usuário de crack em situações de tratamento: experiências, significados e sentidos. Saúde e Sociedade, São Paulo: USP, v. 23, n. 1, p. 118-130, mar. 2014.

Pedroza, R. L. S. A psicologia na formação do professor: uma pesquisa sobre o desenvolvimento pessoal de professores do ensino fundamental. 2003. 191f. Tese (Doutorado em Psicologia) — Universidade de Brasília, Brasília, 2003.

. A formação do professor: possibilidades para o desenvolvimento profissional e pessoal. In: Dessen, M. A.; Maciel, D. A. (Orgs.). A ciência do desenvolvimento bumano: desafios para a psicologia e a educação. Curitiba: Juruá, 2014. p. 327-355.

SiLva, S. F. L. Violência e drogas na escola e imediaçôes: ótica de educadores sociais da segurança pública. 173f. Dissertação (Mestrado em Psicologia Clínica e Cultura) Universidade de Brasília, Brasília, 2011.

Silveira, L. M. O.; Wagner, A. A interação família-escola diante dos problemas de comportamento da criança: estudos de caso. Psicologia da Educação, São Paulo: PUC, n. 35, p. 95-119, dez. 2012.

Soares, C. B.; JACobi, P. R. Adolescentes, drogas e aids: avaliação de um programa de prevenção escolar. Cadernos de Pesquisa, São Paulo: Fundação Carlos Chagas; Campinas: Autores Associados, n. 109, p. 213-237, mar. 2000.

Sousa, T. R.; Pedroza, R. L. S.; Sousa, J. V. A infância em foco: Estado, políticas públicas e educação. Linhas Críticas, Brasília: UnB, v. 20, n. 43, p. 643-663, set./dez. 2014.

SudBrack,M. F. O. Drogas e complexidade: do caos à transformação.In: Brasil. Ministério da Justiça. Secretaria Nacional de Políticas sobre Drogas. Curso de prevenção do uso de drogas para educadores de escolas públicas. 6. ed. Brasília: SENAD/MJ, 2014. p. 162-166.

Sudbrack, M. F. O.; Dalbosco, C. Escola como contexto de proteção: refletindo sobre o papel do educador na prevenção do uso indevido de drogas. In: Simpósıo Internacional do Adolescente, 1., maio 2005, São Paulo. Anais... São Paulo: FEUSP, 2 maio 2005.

Tavares de Lima, F. F. Conversando com as crianças e tentando formá-las para enfrentar os desafios da vida a partir do tema das drogas. In: Silva, E.; Micheli, D. (Orgs.). Adolescências: uso e abuso de drogas — uma visão integrativa. São Paulo: FASP/UNIFESP, 2011. p. 563-577.

VArani, A.; Silva, D. C. A relação família-escola: implicações no desempenho escolar dos alunos dos anos iniciais do ensino fundamental. Revista Brasileira de Estudos Pedagógicos, Brasília: INEP, v. 91, n. 229, p. 511-527, set./dez. 2010.

Vigotski, L. S. Psicologia pedagógica. 2. ed. São Paulo: Martins Fontes, 2004.

Vygotski, L. S. Obras escogidas. 2. ed. v. III. Madrid: Visor, 2000. 


\section{SOBRE OS AUTORES}

Julia Chamusca Chagas é doutoranda em processos de desenvolvimento humano e saúde pela Universidade de Brasília (UnB). Psicóloga da mesma instituição.

E-mail: juliacchagas@gmail.com

Ricardo Henrique Brito Marques é mestre em psicologia clínica e cultura pela Universidade de Brasília (UnB). Psicólogo da Secretaria de Estado de Educação do Distrito Federal (SEEDF).

E-mail: ricardohbmarques@gmail.com

Regina Lúcia Sucupira Pedroza é doutora em psicologia pela Universidade de Brasília (UnB). Professora da mesma instituição.

E-mail:rpedroza@unb.br

Lúcia Helena Cavasin Zabotto Pulino é doutora em filosofia pela Universidade Estadual de Campinas (UNICAMP). Professora da Universidade de Brasília (UnB).

E-mail: luciahelena.pulino@gmail.com

Sandra Francisca Lima da Silva é mestre em psicologia clínica e cultura pela Universidade de Brasília (UnB). Colaboradora da Academia de Polícia Civil do Distrito Federal (APC).

E-mail: sandfranlim@gmail.com

Isabelle Borges Siqueira é mestre em psicologia pela Universidade de Brasília (UnB). Professora da mesma instituição.

E-mail: ibs.siqueira@gmail.com

Taísa Resende Sousa é mestre em processos de desenvolvimento humano e saúde pela Universidade de Brasília (UnB). Professora da mesma instituição.

E-mail: taisarsousa@gmail.com

Maria Fátima Olivier Sudbrack é doutora em psicologia pela Université Paris 13 (França). Professora da Universidade de Brasília (UnB). E-mail:mfosudbrack@gmail.com 